\title{
Dinâmica de plantas daninhas após aplicação de oxadiazon com simulação de lâminas d'água e incorporação de material orgânico
}

\author{
Kassio F. Mendes ${ }^{1}$, Ronaldo M. Reis ${ }^{2}$, Marcelo R. dos Reis ${ }^{3}$, Remon R. da Silva ${ }^{3}$, \\ Wellington L. de Almeida ${ }^{3}$ \& Miriam H. Inoue ${ }^{4}$
}

\footnotetext{
1 Universidade de São Paulo, Centro de Energia Nuclear na Agricultura, Laboratório de Ecotoxicologia, Av. Centenário, 303, São Dimas, CEP 13400-970, Piracicaba-SP, Brasil. Caixa Postal 96. E-mail: kassio_mendes_06@hotmail.com

2 Universidade Federal de Viçosa, Centro de Ciências Agrárias, Programa de Pós-Graduação em Fitotecnia, Avenida P.H. Rolfs, s/n, Centro, 36571-000, Viçosa-MG, Brasil. E-mail: ronaldo.reis@ufv.br

3 Universidade Federal de Viçosa, Rodovia MG 230, km 08, Zona Rural, CEP 38810-000, Rio Paranaíba-MG, Brasil. Caixa Postal 22, E-mail: marceloreis@ufv.br; remon.silva@gmail.com; wellington.almeida@ufv.br

${ }^{4}$ Universidade do Estado de Mato Grosso, Agronomia, Rodovia MT 358, Km 07, Jardim Aeroporto, CEP 78300-000, Tangará da Serra-MT, Brasil. Caixa Postal 287. E-mail: miriamhinoue@hotmail.com
}

\section{RESUMO}

Objetivou-se, neste trabalho, determinar o efeito do oxadiazon no comportamento da comunidade de plantas daninhas em diferentes momentos de aplicação de lâminas d'água e incorporação de material orgânico. Utilizou-se o delineamento em blocos casualizados com tratamentos dispostos em esquema fatorial $5 \times 2$, com 4 repetições. Os tratamentos foram constituídos pela combinação da incorporação (8 tha-1) ou não de material orgânico no solo e do momento de aplicação de lâminas d'água (0; $10 \mathrm{~mm}$ antes; $10 \mathrm{~mm}$ depois e sequencial de $10 \mathrm{~mm}$ antes e depois da aplicação do oxadiazon); além da testemunha ( $0 \mathrm{~mm}$ e $0 \mathrm{~g} \mathrm{ha}{ }^{-1}$ de oxadiazon). Foram obtidas a densidade relativa, a frequência relativa, a abundância relativa, o índice de valor de importância (IVI) e o índice de similaridade (IS) da flora de plantas daninhas. Não houve interação significativa entre o material orgânico e as lâminas d'água. A espécie Cyperus rotundus apresentou maior IVI, independente do tratamento avaliado, seguidas da Urochloa decumbens, Galinsoga parviflora, Bidens pilosa e Melampodium perfoliatum. A maior similaridade (IS $=0,75)$ foi observada entre o tratamento que recebeu a aplicação de $10 \mathrm{~mm}$ de lâmina d'água antes associado com o de $10 \mathrm{~mm}$ depois de aplicação do oxadiazon.

Palavras-chave: herbicida neutro, irrigação, matéria orgânica, similaridade

\section{Dynamics of weeds after application of oxadiazon with simulated water depths and incorporation of organic material}

\begin{abstract}
The objective of this work was to determine the effect of oxadiazon in the behavior of the weed community under different moments of application of water depths and incorporation of organic material. A randomized block design was used with treatments arranged in a factorial $5 \times 2$ with four replications. The treatments consisted of combination of with or without incorporation $\left(8 \mathrm{tha}{ }^{-1}\right)$ of organic material in the soil and the moments of application of water depths $(0$, before $10 \mathrm{~mm}$, after $10 \mathrm{~mm}$, and sequential $10 \mathrm{~mm}$ before and after application of oxadiazon), and the control (0 mm water and $0 \mathrm{~g} \mathrm{ha}^{-1}$ of oxadiazon). Relative density, relative frequency, relative abundance, importance value index (IVI) and similarity index (SI) of the weed flora were obtained. No significant interaction between the organic material and water depths was observed. Cyperus rotundus showed higher IVI, regardless of the experimental treatment, followed by Urochloa decumbens, Galinsoga parviflora, Bidens pilosa and Melampodium perfoliatum. The highest similarity (SI $=0.75$ ) was observed between treatments with the application of $10 \mathrm{~mm}$ water depth before associated with the $10 \mathrm{~mm}$ after the application of oxadiazon.
\end{abstract}

Key words: herbicide neutral, irrigation, organic matter, similarity 


\section{Introdução}

O oxadiazon é inibidor da enzima PROTOX (protoporfirinogênio oxidase) e pertencente ao grupo químico dos oxadiazoles. Em áreas cultivadas com Alliaceae, como alho (Allium sativum), o oxadiazon é amplamente utilizado em pré-emergência na dose de $1.000 \mathrm{~g} \mathrm{ha}^{-1}$, sobretudo por ser bastante eficiente e exclusivo no controle de falso trevo (Oxalis latifolia) (Arya \& Singh, 1998), que é uma das principais plantas daninhas dessa cultura; todavia, o controle de plantas daninhas pelo oxadiazon tem sido insatisfatório pois após 10-15 dias são necessárias aplicações de herbicidas pósemergentes e capinas manuais, onerando o custo de produção.

Apesar da seletividade às culturas, pouco se conhece do comportamento do oxadiazon nos solos brasileiros; ante o exposto tem sido observada uma forte correlação entre o teor de carbono orgânico do solo e a sorção de herbicidas (Ahangar et al., 2008; Tang et al., 2009; Liu et al., 2010; Sun et al., 2012). Estévez et al. (2008) relatam que a sorção de compostos neutros ou não iônicos, como o oxadiazon, parece depender da natureza molecular da matéria orgânica contida no solo. Mendes (2013) verificou correlação positiva entre a matéria orgânica do solo (MOS) e a sorção de oxadiazon em Latossolo Vermelho sendo que o acréscimo de 1,0\% de MOS aumentou aproximadamente $180,0 \mathrm{~g} \mathrm{ha}^{-1}$ na dose do herbicida capaz de reduzir em $50 \%$ do acúmulo de matéria seca das plantas bioindicadoras (DL50).

O oxadiazon é suficientemente sorvido no solo para resistir à lixiviação baseada em deslocamento (Wehtje et al., 1993) apesar disto, em solos intensamente cultivados submetidos a lâminas frequentes de irrigação, como em Alliaceae, pode ocorrer certa movimentação do oxadiazon na superfície do solo; em consequência, pode afetar a atividade do produto no solo e o estabelecimento da comunidade infestante.

$\mathrm{O}$ conhecimento da comunidade de plantas daninhas que ocorre nas áreas de cultivo torna-se a base para a formulação de um programa de controle eficiente (Adegas et al., 2010). No levantamento florístico, além da identificação das espécies infestantes há, também, a necessidade da análise quantitativa dessas espécies, a que se denomina estudo ou método fitossociológico (Braun-Blanquet, 1979). Este método fornece dados específicos das espécies presentes, como frequência, densidade e abundância, além da sua relação com a população total infestante. Assim, o método fitossociológico é uma ferramenta que permite fazer várias inferências sobre a flora de plantas daninhas em questão, que se disseminam rapidamente no meio produtivo (Dangwal et al., 2011).
Para compreender a aplicabilidade desses levantamentos para a ciência das plantas daninhas, tal como sua validade, deve-se escolher os métodos mais adequados e com base ecológica, uma vez que as áreas cultivadas apresentam um grupo relativamente distinto de fatores de seleção em comparação com os ambientes naturais (Concenço et al., 2013). Os resultados de levantamentos fitossociológicos indicam que a cultura antecessora, umidade do solo, $\mathrm{pH}$ do solo e a altitude, influenciam na diversidade e na composição das plantas daninhas (Gupta et al., 2008).

Desta forma objetivou-se, neste trabalho, determinar o efeito do oxadiazon no comportamento da comunidade de plantas daninhas, em diferentes momentos de aplicação de lâminas d'água e incorporação de material orgânico.

\section{Material e Métodos}

$\mathrm{O}$ experimento foi realizado na área experimental da Universidade Federal de Viçosa, no município de Rio Paranaíba, MG (latitude: $19^{\circ} 12^{\prime} 29,0^{\prime \prime} \mathrm{S}$ e longitude: $46^{\circ} 07^{\prime} 57,0^{\prime \prime} \mathrm{O}$ ), em Latossolo Vermelho distroférrico, textura argilosa (Embrapa, 2006), com as características químicas apresentadas na Tabela 1.

Os dados diários de precipitação pluviométrica, temperatura mínima e máxima do ar foram coletados em estação meteorológica localizada próximo à área durante todo o período de realização do experimento (Figura 1).

No preparo do solo utilizou-se o arado de disco; em seguida, a enxada rotativa, na profundidade média de $0,30 \mathrm{~m}$; o encanteiramento foi realizado manualmente. As dimensões de

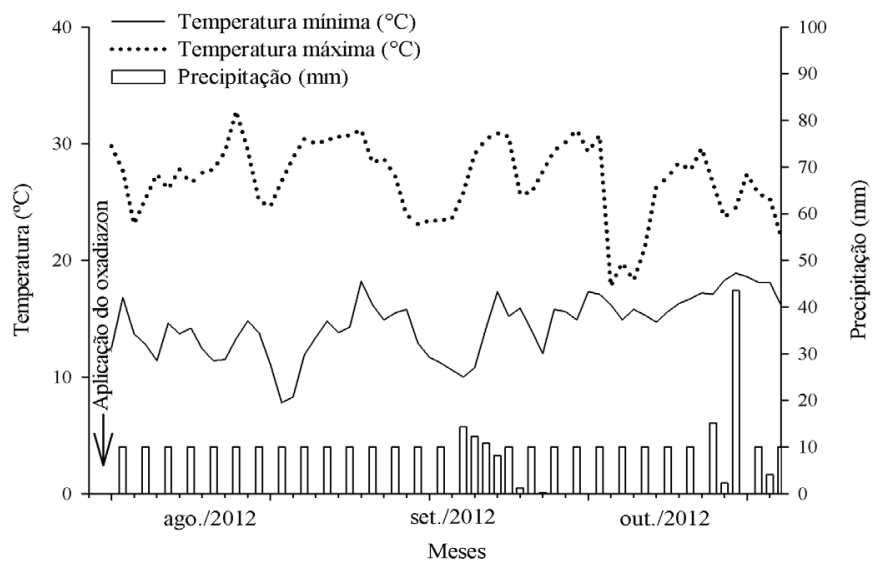

Figura 1. Precipitação pluviométrica $(\mathrm{mm})$, temperatura mínima e máxima $\left({ }^{\circ} \mathrm{C}\right)$ diária do ar durante o período de 20 de agosto a 18 de outubro de 2012. Rio Paranaíba, MG

Tabela 1. Características químicas do Latossolo Vermelho distroférrico da área experimental. Rio Paranaíba, MG, 2012

\begin{tabular}{|c|c|c|c|c|c|c|c|c|c|}
\hline \multirow{2}{*}{ Solo* } & \multicolumn{2}{|c|}{$\mathbf{p H}$} & P(res) & \multirow{2}{*}{$\begin{array}{c}\text { P(melh) } \\
\left(\mathrm{mg} \mathrm{dm}^{-3}\right)\end{array}$} & $\mathbf{P}($ rem $)$ & MO & $\mathrm{CO}$ & $\mathbf{V}$ & \multirow[t]{2}{*}{$\mathbf{m}$} \\
\hline & $\left(\mathrm{H}_{2} \mathrm{O}\right)$ & $\left(\mathrm{CaCl}_{2}\right)$ & & & & \multicolumn{2}{|c|}{$\left(\mathrm{g} \mathrm{dm}^{-3}\right)$} & $(\%)$ & \\
\hline Sem1/ & 6,00 & 5,70 & 98,00 & 50,20 & 12,80 & 43,00 & 24,90 & 78,90 & 0,00 \\
\hline \multirow[t]{3}{*}{ Com² } & 7,20 & 6,30 & 250,00 & 96,50 & 14,90 & 49,00 & 28,40 & 84,60 & 0,00 \\
\hline & $\mathbf{K}$ & $\mathrm{Ca}^{2+}$ & $\mathrm{Mg}^{2+}$ & $\mathrm{Al}^{3+}$ & $\mathbf{H}+\mathbf{A l}$ & SB & & & $\mathbf{T}$ \\
\hline & \multicolumn{9}{|c|}{$\left(\mathrm{cmol}_{\mathrm{c}} \mathrm{dm}^{-3}\right)$} \\
\hline Sem1/ & 0,32 & 5,00 & 1,40 & 0,00 & 1,80 & 6,72 & & & 8,52 \\
\hline $\mathrm{Com} 21$ & 1,37 & 5,90 & 2,30 & 0,00 & 1,74 & 9,57 & & & 11,31 \\
\hline
\end{tabular}

${ }^{*} \mathrm{P}($ res $)$ = fósforo resina; $\mathrm{P}(\mathrm{melh})$ = fósforo Mehlich; $\mathrm{P}($ rem $)$ = fósforo remanescente; $\mathrm{MO}=$ matéria orgânica (Método calorimétrico); $C O=$ carbono orgânico; $V$ = saturação por bases; $m$ = saturação por

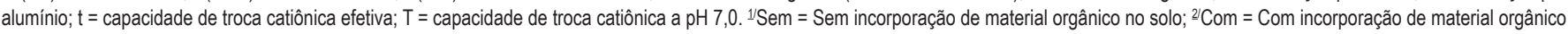
no solo. Fonte: Fertilab - Laboratório de Análises de Solo e Foliar. São Gotardo, MG. 
cada parcela experimental foram de $1,20 \times 2,50 \mathrm{~m}$, totalizando 40 unidades experimentais; posteriormente foram realizadas irrigações de $10 \mathrm{~mm}$ a cada dois dias, em todas as parcelas.

Para a aplicação do oxadiazon $\left(1.000 \mathrm{~g} \mathrm{ha}^{-1}\right)$ em préemergência das plantas daninhas, foi utilizado um pulverizador costal pressurizado com $\mathrm{CO}_{2}$ a $200 \mathrm{kPa}$, equipado com barra de duas pontas de jato plano, 110.02 , espaçadas $0,5 \mathrm{~m}$ entre si com volume de calda equivalente a $200 \mathrm{~L} \mathrm{ha}^{-1}$. A aplicação do oxadiazon foi realizada com umidade do ar de $59 \%$, umidade do solo de $46 \%$, temperatura do ar atmosférico de $28^{\circ} \mathrm{C}$ e velocidade do vento de $3,0 \mathrm{~km} \mathrm{~h}^{-1}$. Para evitar a deriva do herbicida foi utilizada uma proteção plástica retangular com $1,50 \mathrm{~m}$ de altura e equivalente ao tamanho da unidade experimental.

Utilizou-se delineamento em blocos casualizados com tratamentos dispostos em esquema de fatorial $5 \times 2$, com quatro repetições. Os tratamentos foram constituídos pela combinação do momento de aplicação de lâminas d'água (0; $10 \mathrm{~mm}$ antes; $10 \mathrm{~mm}$ depois e sequencial de $10 \mathrm{~mm}$ antes e depois da aplicação do oxadiazon) distribuídas uniformemente e calculadas em função da quantidade de água (L) por unidade de área experimental $\left(\mathrm{m}^{2}\right)$, além da testemunha $(0 \mathrm{~mm}$ e $0 \mathrm{~g}$ $\mathrm{ha}^{-1}$ de oxadiazon) (Tabela 2$)$ e de incorporação $\left(8 \mathrm{tha}^{-1}\right)$ ou não de material orgânico no solo cuja composição foi de $1,0 \%$ de $\mathrm{N} ; \mathrm{pH}$ de 6,$0 ; 15 \%$ de $\mathrm{CO}$ e $40 \%$ de umidade.

Tabela 2. Tratamentos com aplicação de oxadiazon em função do material orgânico no solo e momento de aplicação da lâmina d'água

\begin{tabular}{|c|c|c|c|}
\hline Tratamentos & $\begin{array}{l}\text { Oxadiazon } \\
\left(\mathrm{g} \text { i.a. } \mathbf{h a}^{-1}\right)\end{array}$ & $\begin{array}{l}\text { Lâmina d'água } \\
\text { (mm) }\end{array}$ & $\begin{array}{c}\text { Material orgânico } \\
\text { no solo }\left(\mathbf{t} \mathbf{h a}^{-1}\right)\end{array}$ \\
\hline $11 /$ & 0 & 0 & 0 \\
\hline 2 & 1.000 & 0 & 0 \\
\hline 3 & 1.000 & $10^{*}$ & 0 \\
\hline 4 & 1.000 & $10^{\star \star}$ & 0 \\
\hline 5 & 1.000 & $10 / 10^{* * *}$ & 0 \\
\hline $61 /$ & 0 & 0 & 8 \\
\hline 7 & 1.000 & 0 & 8 \\
\hline 8 & 1.000 & $10^{*}$ & 8 \\
\hline 9 & 1.000 & $10^{* *}$ & 8 \\
\hline 10 & 1.000 & $10 / 10^{* * *}$ & 8 \\
\hline
\end{tabular}

*Antes da aplicação do oxadiazon **Depois da aplicação do oxadiazon ${ }^{* * *}$ Antes e depois da aplicação do oxadiazon. ${ }^{1}$ Testemunhas.

Aos 60 dias após a aplicação do herbicida (DAA), foram realizadas amostragens das plantas daninhas na região central das parcelas $\left(1,00 \mathrm{~m}^{2}\right)$ desprezando-se as bordaduras $(0,20 \mathrm{~m})$. Em cada parcela amostrada as plantas foram quantificadas e identificadas segundo a família, o gênero e a espécie. Coletouse a parte aérea das plantas daninhas para determinação da matéria seca, e esta foi acondicionada separadamente por espécie em sacos de papel que foram levados à estufa com circulação forçada de ar a $72^{\circ} \mathrm{C}$, por $48 \mathrm{~h}$.

No levantamento fitossociológico foram calculadas a densidade de plantas daninhas, a frequência e a abundância das espécies; a partir desses cálculos foram determinados a frequência relativa, a densidade relativa, a abundância relativa e o índice de valor de importância (IVI), com as seguintes fórmulas propostas por Mueller-Dombois \& Ellenberg (1974) e Braun-Blanquet (1979).

$$
\text { Frequência }(\mathrm{Fr})=\frac{\mathrm{N}^{\mathrm{o}} \text { de parcelas que contém a espécie } \times 100}{\mathrm{~N}^{\mathrm{o}} \text { total de parcelas utilizadas }}
$$

Frequência relativa $($ Frr $)=\frac{\text { Frequência da espécie } \times 100}{\text { Frequência total das espécies }}$

Densidade $($ Den $)=\frac{\mathrm{N}^{\mathrm{o}} \text { total de indivíduos por espécie }}{\text { Área total amostrada }}$

Densidade relativa $($ Der $)=\frac{\text { Densidade da espécie } \times 100}{\text { Densidade total das espécies }}$

Abundância $(\mathrm{Abu})=\frac{\mathrm{N}^{\mathrm{o}} \text { total de indivíduos por espécie }}{\mathrm{N}^{\mathrm{o}} \text { total de parcelas contendo a espécie }}$

Abundância relativa $($ Abr $)=\frac{\text { Abundância da espécie } \times 100}{\text { Abundância total das espécies }}$

Índice de valor e importância (IVI) $=$ Frr + Der + Abr

Para a análise de similaridade entre espécies será determinado o índice de similaridade (IS) analisando-se a similaridade das populações de espécies de plantas daninhas entre todos os tratamentos (Sorensen, 1972), a partir da seguinte equação:

$$
\operatorname{IS}(\%)=\left(\frac{2 a}{b+c}\right) \times 100
$$

em que, a é o número de espécies comuns aos tratamentos e b e $\mathrm{c}=$ número total de espécies nos tratamentos comparados. O IS varia de 0 a $100 \%$, sendo máximo quando todas as espécies são comuns aos tratamentos e mínimo quando não existem espécies em comum.

Os dados referentes ao número e à matéria seca de plantas daninhas, foram transformados em $\log (\mathrm{x})$ e submetidos à análise de variância enquanto as médias foram comparadas pelo teste de Scott Knott $(\mathrm{p}<0,05)$.

\section{Resultados e Discussão}

Não houve interação significativa entre os momentos de aplicação de lâminas d'água e a incorporação $\left(49 \mathrm{~g} \mathrm{dm}^{-3} \mathrm{de}\right.$ MO - matéria orgânica) ou não de material orgânico no solo (43 $\mathrm{g} \mathrm{dm}^{-3}$ de $\mathrm{MO}$ ), podendo ser justificado pela semelhança de valores de MO presente no solo.

No levantamento fitossociológico foram identificadas 33 espécies de plantas daninhas nas unidades experimentais, distribuídas em 12 famílias botânicas. As três principais famílias foram, ao número de espécie, Asteraceae, Poaceae e Amaranthaceae, com 9, 6 e 4 espécies cada uma, respectivamente (Tabela 3).

As famílias Asteraceae e Poaceae são de grande importância nas diferentes regiões produtoras do Brasil pois, além das áreas produtoras de grãos, como as de girassol (Adegas et al., 2010), verifica-se a maior ocorrência de espécies de plantas daninhas das famílias Asteraceae e Poaceae em cana-de-açúcar (Soares et al., 2011), pastagem (Inoue et al., 2012) e café (Maciel et al., 2010). 
Tabela 3. Espécies de plantas daninhas encontradas no levantamento fitossociológico aos 60 DAA de oxadiazon, organizadas por família, nome científico e nome comum. Rio Paranaíba, MG, 2012

\begin{tabular}{|c|c|c|}
\hline Família & Nome científico & Nome comum \\
\hline \multirow{4}{*}{ Amaranthaceae } & Alternanthera tenella Colla & apaga-fogo \\
\hline & Amaranthus viridis L. & caruru-de-mancha \\
\hline & Chenopodium álbum L. & ançarinha-branca \\
\hline & Chenopodium ambrosioides L. & erva-de-santa-maria \\
\hline \multirow{9}{*}{ Asteraceae } & Ageratum conyzoides $\mathrm{L}$. & mentrasto \\
\hline & Bidens pilosa $\mathrm{L}$. & picão-preto \\
\hline & Conyza bonariensis (L.) Cronquist & buva \\
\hline & Emilia sonchifolia (L.) DC & falsa-serralha \\
\hline & Galinsoga parviflora Cav. & botão-de-ouro \\
\hline & Gnaphalium spicatum Lain. & macelinha \\
\hline & Melampodium perfoliatum (Carv.) A. Gray & estrelinha \\
\hline & Parthenium hysterophorus $\mathrm{L}$. & losna branca \\
\hline & Sonchus oleraceus $\mathrm{L}$. & serralha \\
\hline \multirow{3}{*}{ Brassicaceae } & Coronopus didymus (L.) Sm. & mentruz \\
\hline & Lepidium virginicum $\mathrm{L}$. & mastruz \\
\hline & Raphanus raphanistrum L. & nabiça \\
\hline \multirow{2}{*}{ Commelinaceae } & Commelina benghalensis $\mathrm{L}$. & trapoeraba \\
\hline & Commelina difusa Burm. F. & trapoeraba-do-brejo \\
\hline Convolvulaceae & Ipomoea triloba L. & corda-de-viola \\
\hline Cyperaceae & Cyperus rotundus $\mathrm{L}$. & tiririca \\
\hline \multirow{2}{*}{ Euphorbiaceae } & Chamaesyce hirta (L.) Millsp. & erva-de-santa-luzia \\
\hline & Euphorbia heterophylla L. & leiteiro \\
\hline Malvaceae & Sida rhombifolia L. & guanxuma \\
\hline \multirow{6}{*}{ Poaceae } & Brachiaria decumbens Stapf. & braquiária decumbens \\
\hline & Brachiaria plantaginea (Link) Hitch. & braquiária plantaginea \\
\hline & Cenchrus echinatus L. & capim-carrapicho \\
\hline & Digitaria spp. & capim-colchão \\
\hline & Eleusine indica (L.) Gaertn. & capim-pé-de-galinha \\
\hline & Eragrostis pilosa (L.) P. Beauv. & capim-mimoso \\
\hline Portulacaceae & Portulaca oleracea L. & beldroega \\
\hline Rubiaceae & Richardia brasilienses Gomez & poaia-branca \\
\hline \multirow{2}{*}{ Solanaceae } & Solanum americanum Mill. & maria-pretinha \\
\hline & Solanum sisymbrifolium Lam. & joá-bravo \\
\hline
\end{tabular}

$\mathrm{Na}$ testemunha sem aplicação de oxadiazon e de lâmina d'água, observou-se maior biodiversidade de plantas daninhas, com 30 espécies (Tabela 4). No entanto, nos tratamentos que receberam aplicação de oxadiazon não houve menor número de espécies nas famílias, como previsto, exceto nas famílias Amaranthaceae, Poaceae, Solanaceae e Euphorbiaceae. Uma hipótese seria a de que, aos 60 DAA (momento de avaliação da flora) um novo fluxo de germinação e emergência de plantas daninhas tenha ocorrido na área considerando-se que a persistência do oxadiazon é de aproximadamente 60 dias após a aplicação dependendo da dose aplicada, do tipo de solo e das condições climáticas (Das et al., 2003).
O número e a matéria seca de plantas daninhas foram menores com a aplicação do oxadiazon, sendo que os menores valores dessas variáveis foram encontrados nos tratamentos com a associação da aplicação de lâmina d'água e do herbicida (Tabela 5). Com a aplicação sequencial de lâmina d'água de $10 / 10 \mathrm{~mm}$, houve menor número $(35,25)$ de plantas daninhas por $\mathrm{m}^{2}$, não diferindo da aplicação de lâmina d'água de 10 $\mathrm{mm}$ antes e $10 \mathrm{~mm}$ depois - 43,12 e 43,50 plantas por $\mathrm{m}^{2}$, respectivamente. A matéria seca das plantas daninhas das parcelas com a aplicação de lâmina d'água de 10/10, diferiu dos demais tratamentos sendo $53 \%$ menor em relação à aplicação do oxadiazon sem lâmina d'água e $79 \%$ menor em relação à testemunha (Tabela 5).

Tabela 5. Número e matéria seca de plantas daninhas aos 60 DAA de oxadiazon (1.000 $\mathrm{g} \mathrm{ha}^{-1}$ ) em função do momento de aplicação de lâmina d'água. Rio Paranaíba, MG, 2012

\begin{tabular}{|c|c|c|}
\hline Tratamento ${ }^{2}$ & $\begin{array}{l}\text { Número de plantas } \\
\text { daninhas }^{1 /}\left(\mathbf{m}^{2}\right)\end{array}$ & $\begin{array}{c}\text { Matéria seca }(\mathrm{g}) \text { de } \\
\text { plantas daninhas }{ }^{1 /}\left(\mathrm{m}^{2}\right)\end{array}$ \\
\hline Testemunha & $137,87 \quad A$ & $13,27 \quad A$ \\
\hline $0 \mathrm{~mm}$ & $57,50 \quad$ B & 5,18 \\
\hline $10 \mathrm{~mm}$ antes & $43,12 \quad C$ & $4,16 \mathrm{C}$ \\
\hline $10 \mathrm{~mm}$ depois & 43,50 & $4,09 \mathrm{C}$ \\
\hline $10 / 10 \mathrm{~mm}$ & $35,25 \mathrm{C}$ & $2,78 \quad \mathrm{D}$ \\
\hline $\mathrm{CV}(\%)$ & 19,95 & 16,69 \\
\hline
\end{tabular}

1/Dados transformados em log $(\mathrm{x}) . \stackrel{2}{2} 10 \mathrm{~mm}$ antes = antes da aplicação do oxadiazon; $10 \mathrm{~mm}$ depois = depois da aplicação do oxadiazon; $10 / 10 \mathrm{~mm}$ = antes e depois da aplicação do oxadiazon. As médias seguidas da mesma letra maiúscula na coluna não diferem estatisticamente entre si, pelo teste de Scott-Knott $(p<0,05)$

Mendes (2013) relatou, através de bioensaio (Avena sativa L.) que a aplicação sequencial de $10 / 10 \mathrm{~mm}$ de lâmina d'água antes e depois da aplicação do oxadiazon, promoveu a incorporação do produto na camada de 0,00 a $0,20 \mathrm{~m}$ do solo. Maior incorporação de herbicida pré-emergente no solo pode aumentar a eficácia do controle das plantas daninhas em virtude da maior quantidade de sementes do solo em contato com o produto. Segundo Prata et al. (2003), os herbicidas necessitam de maior movimentação no solo para que possam atingir as sementes ou a zona de absorção radicular das plantas daninhas com vista ao melhor desempenho do produto.

$\mathrm{O}$ oxadiazon proporcionou baixa eficiência no controle de Cyperus rotundus (tiririca), visto que em todos os tratamentos foram constatados, com a aplicação do oxadizon, maiores

Tabela 4. Número de espécies de plantas daninhas organizadas por família aos 60 DAA de oxadiazon, em função do momento de aplicação da lâmina d'água. Rio Paranaíba, MG, 2012

\begin{tabular}{|c|c|c|c|c|c|c|}
\hline \multirow[b]{2}{*}{ Família } & \multicolumn{6}{|c|}{ Número de espécies de plantas daninhas por tratamento ${ }^{\text {/ }}$} \\
\hline & Testemunha & $0 \mathrm{~mm}$ & $10 \mathrm{~mm}$ antes & $10 \mathrm{~mm}$ depois & $10 / 10 \mathrm{~mm}$ & $\begin{array}{l}\text { Espécies } \\
\text { comuns }\end{array}$ \\
\hline Amaranthaceae & 4 & 0 & 1 & 0 & 2 & 0 \\
\hline Asteraceae & 8 & 7 & 7 & 8 & 6 & 4 \\
\hline Brassicaceae & 3 & 3 & 2 & 3 & 3 & 2 \\
\hline Commelinaceae & 1 & 2 & 1 & 2 & 1 & 1 \\
\hline Convolvulaceae & 0 & 0 & 0 & 0 & 1 & 0 \\
\hline Cyperaceae & 1 & 1 & 1 & 1 & 1 & 1 \\
\hline Euphorbiaceae & 2 & 1 & 1 & 1 & 1 & 1 \\
\hline Malvaceae & 1 & 1 & 1 & 1 & 0 & 0 \\
\hline Poaceae & 6 & 4 & 4 & 4 & 4 & 4 \\
\hline Portulacaceae & 1 & 0 & 0 & 0 & 0 & 0 \\
\hline Rubiaceae & 1 & 1 & 1 & 1 & 1 & 1 \\
\hline Solanaceae & 2 & 1 & 1 & 1 & 1 & 1 \\
\hline Total & 30 & 21 & 20 & 22 & 21 & 15 \\
\hline
\end{tabular}

$1 / 10 \mathrm{~mm}$ antes = antes da aplicação do oxadiazon; $10 \mathrm{~mm}$ depois = depois da aplicação do oxadiazon; 10/10 mm = antes e depois da aplicação do oxadiazon. 
Índices de Valor de Importância (IVI) desta espécie (Figura 2). Este comportamento de C. rotundus pode ter sido intensificado pelo revolvimento do solo cujo efeito favorece sua propagação e estabelecimento em razão da quebra da dormência pela divisão de tubérculos e eliminação da dominância apical (Silva et al., 2005). Além disto, em condições de altas temperaturas, como as verificadas em Rio Paranaíba, MG (Figura 1), plantas que possuem o ciclo $\mathrm{C} 4$ de fixação de carbono, como C. rotundus, tem seu crescimento favorecido devido às altas taxas fotossintéticas (Meirong, 1993). Para maior controle desta planta daninha são necessárias medidas preventivas, como a limpeza de equipamentos e implementos, evitando que propágulos sejam transferidos de uma área infestada para outra não infestada. Em algumas áreas de Alliaceae, no Alto Paranaíba (MG), realiza-se a catação manual de tubérculos de C. rotundus. O sistema de plantio direto tem proporcionado redução de até $94 \%$ na brotação dos tubérculos de C. rotundus (Jakelaitis et al., 2003). Apesar das inúmeras vantagens deste sistema, o mesmo não se aplica em áreas de cultivo de hortaliças tuberosas, que exigem preparo intensivo de solo para melhor desenvolvimento dos bulbos, tubérculos, rizomas e raízes.

Entre as dez principais espécies de plantas daninhas apenas as $C$. rotundus, Urochloa decumbens, Galinsoga parviflora, Bidens pilosa e Melampodium perfoliatum ocorreram em todos os tratamentos (Figura 2). Com relação a C. rotundus, observa-se que o IVI foi maior que $50 \%$ nos tratamentos que receberam lâminas d'água sendo que a aplicação de lâmina d'água de $10 \mathrm{~mm}$ depois (Figura 2A) e sequencial de $10 \mathrm{~mm}$ antes e depois da aplicação do oxadiazon (Figura 2D) proporcionou maiores IVI, 62,77 e $51,77 \%$, respectivamente. Os maiores valores de IVI refletem a maior densidade relativa (Der), pronunciada nos tratamentos com a aplicação de lâmina d'água.

Urochloa decumbens foi a segunda espécie de maior relevância nos tratamentos sem a aplicação de lâmina d'água (Figura 2A), de modo que na associação da aplicação do oxadiazon e as lâminas d'água, a espécie apresentou menor IVI (Figuras 2b, c e d). As espécies G. parviflora e M. perfoliatum obtiveram importância relativa média nos diferentes tratamentos, com IVI variando de 20 a $35 \%$. Mueller et al. (2001), relataram que o picão-branco (Galinsoga parviflora) foi a espécie que mais rapidamente se estabeleceu nos tratamentos tratados com o oxadiazon $\left(750 \mathrm{~g} \mathrm{ha}^{-1}\right)$. A densidade relativa e a abundância relativa de $B$. pilosa apresentaram valores menores nos tratamentos que receberam aplicação de lâminas d'água cuja aplicação de $10 \mathrm{~mm}$ antes do oxadiazon proporcionou os menores valores de densidade relativa $\left(1,25\right.$ planta $\left.\mathrm{m}^{-2}\right) \mathrm{e}$ abundância relativa $(2,00)$ e, em contrapartida, o menor IVI $(12,19 \%)$ da espécie (Figura 2B). Mesmo em baixa densidade de plantas e B. pilosa apresenta grande capacidade de extração de nutrientes, o que também foi verificado por Ronchi et al. (2003), cuja densidade de apenas uma planta de B. pilosa em convivência com planta de café, no mesmo vaso por 77 dias, proporcionou redução de 41, 28, 33, 33, 26 e 3\% no acúmulo de $\mathrm{N}, \mathrm{P}, \mathrm{K}, \mathrm{Ca}, \mathrm{Mg}$ e S, respectivamente, pelo cafeeiro.

Por meio do Índice de Similaridade (IS) foi possível relatar que há espécies daninhas similares existentes entre os tratamentos avaliados (Tabela 6). Os coeficientes de
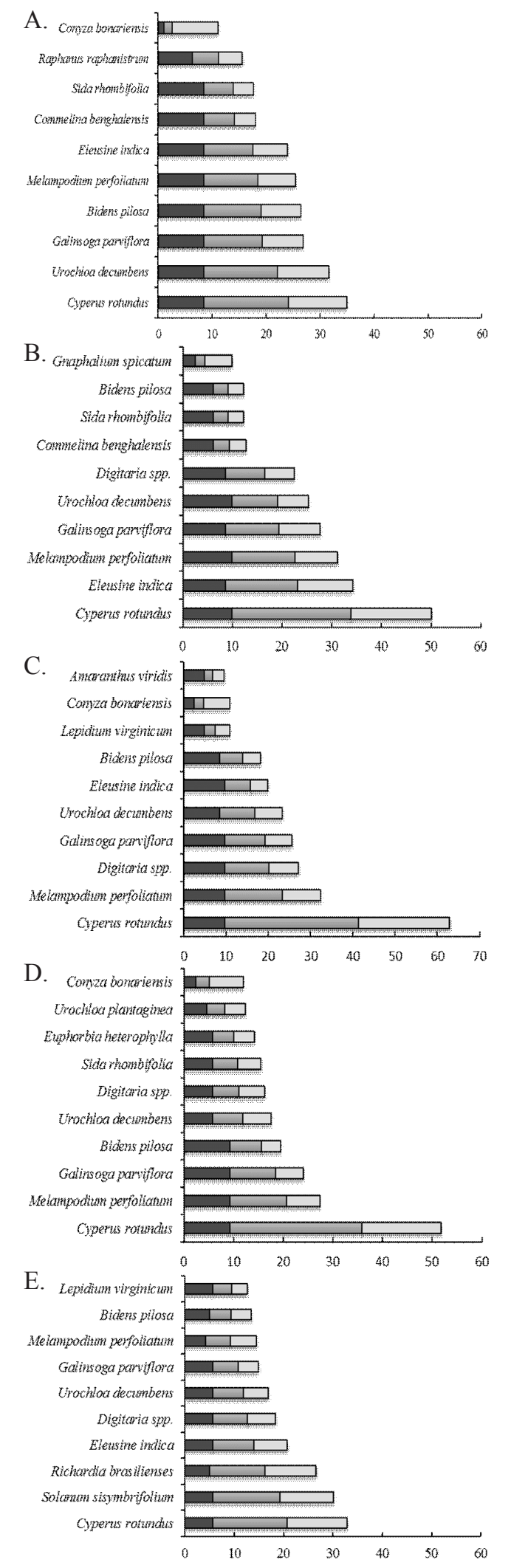

Frequência Relativa

$\square$ Densidade Relativa

$\square$ Abundância Relativa

Figura 2. Indice de valor de importânica (IVI) das principais plantas daninhas aos 60 DAA de oxadiazon, Rio Paranaíba, MG, 2012. A) Aplicação de 0 $\mathrm{mm}$ de lâmina d'água; B) Aplicação de $10 \mathrm{~mm}$ de lâmina d'água antes da aplicação do oxadiazon; C) Aplicação de $10 \mathrm{~mm}$ de lâmina d'água depois da aplicação do oxadiazon; D) Aplicação de $10 \mathrm{~mm}$ de lâmina d'água antes e depois da aplicação do oxadiazon e E) Testemunha (0 $\mathrm{mm}$ e $0 \mathrm{~g} \mathrm{ha}^{-1}$ ) 
Tabela 6. Coeficiente de similaridade fitossociológica entre os tratamentos aos 60 DAA de oxadiazon, em função do momento de aplicação da lâmina d'água. Rio Paranaíba, MG, 2012

\begin{tabular}{lccccc}
\hline Tratamento $^{-1}$ & Testemunha & $\mathbf{0 ~} \mathbf{~ m m}$ & $\mathbf{1 0 ~} \mathbf{~ m m}$ antes & $\mathbf{1 0} \mathbf{~ m m ~ d e p o i s ~}$ & $\mathbf{1 0} / \mathbf{1 0} \mathbf{~ m m}$ \\
\hline Testemunha & 1,0000 & 0,4235 & 0,4102 & 0,4121 & 0,2960 \\
$0 \mathrm{~mm}$ & & 1,0000 & 0,6410 & 0,5446 & 0,5283 \\
$10 \mathrm{~mm}$ antes & & & 1,0000 & 0,7532 & 0,6156 \\
$10 \mathrm{~mm}$ depois & & & & 1,0000 & 0,6159 \\
$10 / 10 \mathrm{~mm}$ & & & & 1,0000 \\
\hline
\end{tabular}

1/10 mm antes = antes da aplicação do oxadiazon; $10 \mathrm{~mm}$ depois = depois da aplicação do oxadiazon; 10/10 mm = antes e depois da aplicação do oxadiazon.

similaridades foram maiores que 0,5 entre os tratamentos que receberam aplicação de oxadiazon. Esta alta similaridade, maior que 50\% (Felfili \& Venturoli, 2000), pode ser explicada pela especificidade de ação do oxadiazon sobre as plantas daninhas visto que as espécies Cenchrus echinatus, Portulaca oleracea, Chenopodium ambrosioides e Chenopodium album ocorreram apenas na testemunha, por serem espécies susceptíveis ao herbicida. O maior coeficiente de similaridade $(0,75)$ foi encontrado no tratamento que recebeu a aplicação de $10 \mathrm{~mm}$ de lâmina d'água antes associado ao de $10 \mathrm{~mm}$ depois da aplicação do oxadiazon (Tabela 6). Tal fato pode ser justificado pelo comportamento do oxadiazon no solo, em que o mesmo volume de água aplicado, independente do momento (antes ou depois da aplicação do oxadiazon), proporcionou alta semelhança na comunidade de plantas daninhas presentes na área e apresentaram, em ambos os tratamentos, números de plantas e matérias secas iguais (Tabela 5).

\section{Conclusões}

Conclui-se que a aplicação de oxadiazon afetou negativamente o número e a matéria seca de plantas daninhas, sendo que este efeito foi intensificado com a aplicação sequencial de lâmina d'água de $10 \mathrm{~mm}$ antes e depois. As três principais famílias encontradas no levantamento fitossociológico foram, quanto ao número de espécie, Asteraceae, Poaceae e Amaranthaceae. A espécie Cyperus rotundus foi a que apresentou maior IVI independente do tratamento avaliado, seguidas da Urochloa decumbens, Galinsoga parviflora, Bidens pilosa e Melampodium perfoliatum. O IS mais expressivo $(0,75)$ foi encontrado entre os tratamentos que receberam a aplicação de $10 \mathrm{~mm}$ antes e 10 mm depois de lâmina.

\section{Agradecimentos}

Os autores agradecem à Fundação de Apoio à Universidade Federal de Viçosa/FUNARBE e à Fundação de Amparo à Pesquisa no Estado de Minas Gerais/FAPEMIG, pelo apoio financeiro à realização da pesquisa.

\section{Literatura Citada}

Adegas, F. S.; Oliveira, M. F.; Vieira, O. V.; Prete, C. E. C.; Gazziero, D. L. P.; Voll, E. Levantamento fitossociológico de plantas daninhas na cultura do girassol. Planta Daninha, v.28, n.4, p.705-716, 2010. <http://dx.doi.org/10.1590/ S0100-83582010000400002>.
Ahangar, A. G.; Smernik, R. J.; Kookana, R. S.; Chittleborough, D. J. Separating the effects of organic matter-mineral interactions and organic matter chemistry on the sorption of diuron and phenanthrene. Chemosphere, v.72, n.6, p.886-890, 2008. <http://dx.doi.org/10.1016/j. chemosphere.2008.03.059>.

Arya, M. P. S.; Singh, R. V. Direct and residual effect of oxadiazon and oxyfluorfen herbicides on the control of Oxalis latifolia in soybean. Indian Journal of Weed Science, v.30, n.1/2, p.36-38, 1998. <http://www.indianjournals. com/ijor.asp $x$ ?target $=$ ijor:ijws $\&$ volume $=30 \&$ issue $=1$ and 2 \&article $=010>$. 09 Jul. 2013.

Braun-Blanquet, J. Fitosociologia: bases para el estudio de las comunidades vegetales. Madrid: H. Blume, 1979. 820p.

Concenço, G.; Tomazi, M.; Correia, I. V. T.; Santos, S. A.; Galon, L. Phytosociological surveys: tools for weed science? Planta Daninha, v.31, n.2, p.469-482, 2013. $<$ http://dx.doi.org/10.1590/S0100-83582013000200025>.

Dangwal, L. R.; Singh, A.; Singh, T.; Sharma, A. Common weeds of kharif crops of Block Sunderbani District Rajouri (Jammu and Kashmir). Pakistan Journal of Weed Science Research, v.17, n.1, p.9-15, 2011. <https:// itunes.apple.com/us/book/common-weeds-kharif-crops/ id $483563440 ? \mathrm{mt}=11>$. 06 Jan. 2013.

Das, A. C.; Debnath, A.; Mukherjee, D. Effect of the herbicides oxadiazon and oxyfluorfen on phosphates solubilizing microorganisms and their persistence in rice fields. Chemosphere, v.53, n.3, p.217-221, 2003. <http://dx.doi. org/10.1016/S0045-6535(03)00440-5>.

Empresa Brasileira de Pesquisa Agropecuária - Embrapa. Centro Nacional de Pesquisa de Solos. Sistema Brasileiro de Classificação de solos. 2. ed. Rio de Janeiro: Embrapa, 2006. 306p.

Estévez, M. A.; Periago, E. L.; Carballo, E. M.; Gándara, J. S.; Mejuto, J. C.; Río, L. G. The mobility and degradation of pesticides in soils and the pollution of groundwater resources. Agriculture, Ecosystems and Environment, v.123, n.4, p.247-260, 2008. <http://dx.doi.org/10.1016/j. agee.2007.07.011>.

Felfili, J. M.; Venturoli, F. Tópicos em análise de vegetação. Comunicações Técnicas Florestais, v.2, n.2, p.1-25, 2000.

Gupta, A.; Joshi, S. P.; Manhas, R. K. Multivariate analysis of diversity and composition of weed communities of wheat fields in Doon Valley, India. Tropical Ecology, v.49, n.2, p.103-112, 2008. <http://tropecol.com/pdf/open/ PDF_49_2/02\%20Gupta.pdf>. 28 Mai. 2013.

Inoue, M. H.; Silva, B. E.; Pereira, K. M.; Santana, D. C.; Conciani, P. A.; Sztoltz, C. L. Levantamento fitossociológico em pastagem. Planta Daninha, v.30, n.1, p.55-63, 2012. $<$ http://dx.doi.org/10.1590/S0100-83582012000100007>. 
Jakelaitis, A.; Ferreira, L. R.; Silva, A. A.; Agnes, E. L.; Miranda, G. V.; Machado, A. F. L. Dinâmica populacional de plantas daninhas sob diferentes sistemas de manejo nas culturas de milho e feijão. Planta Daninha, v.21, n.1, p.71-79, 2003. $<\mathrm{http}$ ://dx.doi.org/10.1590/S0100-83582003000100009>.

Liu, Y.; Xu, Z.; Wu, X.; Gui, W.; Zhu, G. Adsorption and desorption behavior of herbicide diuron on various Chinese cultivated soils. Journal of Hazardous Materials, v.178, n.1-3， p.462-468, 2010. <http://dx.doi.org/10.1016/j. jhazmat.2010.01.105>.

Maciel, C. D. G.; Poletine, J. P.; Oliveira Neto, A. M.; Guerra, N.; Justiniano, W. Levantamento fitossociológico de plantas daninhas em cafezal orgânico. Bragantia, v.69, n.3, p.631-636, 2010. <http://dx.doi.org/10.1590/S0006$87052010000300015>$.

Meirong, L. Leaf photosynthetic nitrogen-use efficiency of $\mathrm{C}_{3}$ and $\mathrm{C}_{4}$ Cyperus species. Photosynthetica, v.29, n.1, p.117-130, 1993. <http://www.cedarcreek.umn.edu/biblio/ fulltext/t1733.pdf $>.15$ Abr. 2013.

Mendes, K. F. Sorção, lixiviação e efeito residual do oxadiazon no solo. Rio Paranaíba: Universidade Federal de Viçosa, 2013. 84p. Dissertação Mestrado.

Mueller, S.; Durigan, J. C.; Kreuz, C. L.; Banzatto, D. A. Épocas de consórcio de alho com cenoura em três sistemas de manejo de plantas daninhas em Jaboticabal-SP. Planta Daninha, v.19, n.1, p.39-50, 2001. <http://dx.doi. org/10.1590/S0100-83582001000100005>.

Mueller-Dombois, D.; Ellenberg, H. A. Aims and methods of vegetation ecology. New York: John Wiley, 1974. 547p.

Prata, F.; Cardinali, V. C. B.; Lavorenti, A.; Tornisielo, V. L.; Regitano, J. B. Glyphosate sorption and desorption in soils with different phosphorous levels. Scientia Agricola, v.60, n.1, p.175-180, 2003. <http://dx.doi.org/10.1590/S010390162003000100026>.
Ronchi, C. P.; Terra, A. A.; Silva, A. A.; Ferreira, L. R. Acúmulo de nutrientes pelo cafeeiro sob interferência de plantas daninhas. Planta Daninha, v.21, n.2, p.219-227, 2003. $<$ http://dx.doi.org/10.1590/S0100-83582003000200007>.

Silva, A. A.; Silva, C. S. W.; Souza, C. M.; Souza, B. A.; Fagundes, J. L.; Falleiro, R. M.; Sediyama, C. S. Aspectos fitossociológicos da comunidade de plantas daninhas na cultura do feijão sob diferentes sistemas de preparo do solo. Planta Daninha, v.23, n.1, p.17-24, 2005. <http:// dx.doi.org/10.1590/S0100-83582005000100003>.

Soares, M. B. B.; Finoto, E. L.; Bolonhezi, D.; Carrega, W.; Albuquerque, J. A. A.; Pirotta, M. Z. Fitossociologia de plantas daninhas sob diferentes sistemas de manejo de solo em áreas de reforma de cana crua. Revista Agro@mbiente Online, v.5, n.3, p.173-181, 2011. <http://revista.ufrr.br/index. php/agroambiente/article/view/594/609>. 28 Jun. 2013.

Sorensen, T. A method of establishing groups of equal amplitude in plant society based on similarity of species content. In: Odum, E. P. (Ed.). Ecologia. 3.ed. México: Interamericana, 1972. p. 572-640.

Sun, K.; Gao, B.; Ro, K. S.; Novak, J. M.; Wang, Z.; Herbert, S.; Xing, B. Assessment of herbicide sorption by biochars and organic matter associated with soil and sediment. Environmental Pollution, v.163, p.167-173, 2012. <http:// dx.doi.org/10.1016/j.envpol.2011.12.015>.

Tang, Z. W.; Zhang, W.; Chen, Y. M. Adsorption and desorption characteristics of monosulfuron in Chinese soils. Journal of Hazardous Materials, v.166, n.2-3, p.1351-1356, 2009. $<$ http://dx.doi.org/10.1016/j.jhazmat.2008.12.052>.

Wehtje, G. R.; Gilliam, C. H.; Hajek, B. F. Adsorption, desorption, and leaching of oxadiazon in container media and soil. HortScience, v.28, n.3, p.126-128, 1993. $<$ http://hortsci.ashspublications.org/content/28/2/126.full. pdf + html $>.01$ Jul. 2013. 